\title{
The Use of Baclofen in Treatment of Spasticity in Multiple Sclerosis
}

\author{
G. M. SAWA AND D. W. PATY
}

SUMMARY: Baclofen was used in a double-blind crossover placebo-controlled trial to treat spasticity in patients with multiple sclerosis (MS). While on Baclofen, patients obtained a significant $(p<0.001)$ reduction in spasticity compared to controls. The drug was particularly effective in alleviating flexor and extensors spasms, as well as their associated pain. Side effects were common in this study, but were usually well tolerated by the patients. The commonest side effects

RÉSUMÉ: L'emploi du Baclofen et le traitement de la spasticité dans la Sclérose en plaques.

Le Baclofen fut employé dans le traitement de la spasticité de patients atteints de sclérose en plaques lors d'un essai à double insu avec technique croisée et contrôle placebo. Lors de ces essais, les patients au Baclofen eurent une diminution significative $(p<0.001)$ de la spasticité, par rapport aux sujets témoins. Le médicament s'est révélé particuliérement efficace contre les spasmes en fléxion ou en extension, ainsi que contre la dopleur qui les accompagne. ll y eu au cours de cetle étude de nombreux were sedation, nausea and vomiting. There were no changes in hepatic, renal, or hematological function in any patients. Increased weakness due to loss of spasticity for support was also a fairly common complaint. The drug seems best indicated in patients in whom spasticity is not required for support or other activities of daily living. Careful monitoring of the patient is essential for effective use of this drug.

effets secondaires, mais il étaient généralement tolérés par les patients. Les effets secondaires les plus fréquents furent la sedaation, la nausée et le vomissement. Il n'y eut aucune modification des fonctions hépatiques, rénales ou hématologiques. Une plainte commune fut l'augmentation de la faiblesse des membres inférieurs due à la perte de la spasticité qui permettait le soutien. Le médicament est donc préférable chez les patients pour qui la spasticité n'est pas nécessaire à la station debout ou pour les autres activités quotidiennes. Il est essentiel de suivre de près chacun des patients pour assurer les meilleus résultats.
From the Department of Clinical Neurological Sciences, University Hospital, London, Ontario

Presented at the XIII Canadian Congress of Neurological Sciences Vancouver, June 1978.

Reprint requests to: Dr. D. W. Paty, Department of Clinical Neurological Sciences, University Hospital, 339 Windermere Rd., London, Ontario, Canada N6A 5A5.

\section{INTRODUCTION}

The medical treatment of spasticity, a disabling problem of patients with multiple sclerosis (MS), is, at present, inadequate. Poor understanding of the pathogenesis of spasticity is acknowledged (Laundau, 1974; Lancet Editorial, 1970).

Diazepam and dantrolene sodium are the major drugs presently in use. Their troublesome and sometimes serious side effects, as well as ineffectiveness in many cases, limit their usefulness (Calne, 1975; Sachais, 1977). The ideal drug in the treatment of spacsticity is still being sought. Baclofen, a GABA analogue, has been suggested as one possible drug.

The use of baclofen in the treatment of spasticity has evolved in the following manner. GABA was the first neurostransmittor thought to have inhibitory properties. GABA does not readily cross the blood brain barrier (Roberts, 1975), but baclofen (available in Canada as Lioresal, CibaGeigy) does. Assuming an action similar to GABA, baclofen began to be used in the treatment of spasticity in several countries, beginning in 1966.

The mechanism of action of baclofen is still not understood. Reduction of presynaptic inhibition was suggested as a major factor contributing to the hyperexcitability of motor neurons, with spasticity the result (Burke and Ashby, 1972). Since one of GABA's major actions was to increase presynaptic inhibition (Curtis, 1971), it was assumed that baclofen would act in a similar manner. This assumption has not been borne out by recent research (Burke et al, 1971; Ashby and White, 1973; Davidoff, 1974; Curtis, 1974). Baclofen may be a selective inhibitor of an excitatory neurotransmitter, 
substance "P" (Saito, 1975) or its effect may be mediated by its phenylethylamine moiety, rather than its GABAanalogue portion (Curtis, 1974).

The metabolism of baclofen has recently been reviewed (Faigle, 1971; Sachais, 1977). The drug is effective orally, and has been shown to have no serious side effects in terms of hepatic, renal, or hematological function. Nausea and vomiting, as well as sedation, are the commonest side effects reported in the literature. Baclofen has been shown to be useful in treating spasticity from a variety of causes: MS, spinal disorders such as trauma, and spasticity secondary to stroke (Pinto, 1971; Hudgson, 1971; From, 1975; Pederson, 1970).

The drug has been reported to be most beneficial in spasticity secondary to MS (Feldman, 1978; Sachais, 1977; Palacek, 1971). Clinical experience with the drug in Canada has been limited (Ashby, 1973; Lapierre, 1974).

The authors set out to gain more experience with this drug in treating spastcitity in patients with MS. Baclofen was effective in treating spasticity in our patients, and it was particularly effective in relieving extensor and flexor spasms. A major problem, as with other antispastic agents, has been that reduction in spasticity may result in weakness. Deterioration of activities such as sitting and walking may ensue. This has been noted by previous authors (Pedersen, 1970). The side effects have been frequent, but are usually well tolerated. Close monitoring of the patient is manditory for most effective use.

\section{METHOD}

A double-blind cross over placebocontrolled format was employed to study lower limb spasticity in 21 patients with clinically definite MS or chronic myelopathy (presumed MS). The patients were otherwise well. Informed consent was obtained in each case. Drugs such as diazepam or steriods which could effect muscle tone were stopped at least seven days prior to entering the trial. Each subject was randomly allocated to the use of baclofen or placebo for twenty-one days. After a wash-out period of seven days, a second phase, using the alternate treatment, was instituted. Baclofen (10 mg. tablets) was given orally and was identical to placebo in size, shape, color and taste. Each drug was adminitstered in gradually increasing doses (beginning with $5 \mathrm{mg}$. three times a day with meals) until the patient reached $60 \mathrm{mg}$. or until intolerable side effects resulted. The patients were seen weekly and blood pressure, pulse, and weight were assessed each time. Biochemical analysis of hepatic, renal, and hematological function was performed before, during the wash-out period, and at the end of the trial.

A reliable test of spasticity is not yet available. The authors chose a test which was considered objective, reproducible, and easily done at the bedside. Spasticity in the legs was graded at the end of each phase, independently by two observers, in the following manner. After the patient had rested in bed, supine for five minutes, spasticity was graded 1 to 5 by an assessment of tone in the extensor muscles of the knee. The leg was passively flexed at the hip and the degree of tone in the quadriceps muscles was assessed by the time taken for the leg to fall to the bed. The time required for the heel to touch the bed was recorded and graded appropriately (see Table 1). When there was a difference in the score between the legs, the higher score was recorded. Other parameters such as extensor and flexor spasms, gait function, and bladder function were also evaluated by history and physical examination and recorded on a separate protocol provided by Ciba-Geigy Company (see Saichais, 1977, for details). These latter results were analysed separately from the assessment of quadriceps tone.

\section{RESULTS}

Twenty one subjects entered the trial, fifteen male and six female, with a mean age of forty-nine and thrity-six years, respectively. The mean duration of illness in the males and females was fourteen and nine years, respectively.

The mean grade of spasticity before treatment with baclofen was three and after treatment was two, with a mean score change of one. The mean grade of spasticity before the use of placebo was three and was unchanged by the use of placebo.

While on placebo, no subject exhibited a detectable change in spasticity. While on the active agent, thirteen out of eighteen patients showed an objective improvement in spasticity (sign test $\mathrm{p}<.001$ ). Only one patient used a contaminating drug during this study (diazepam, 5 to 7 mg., used for night-time sedation). There were 3 withdrawals from the study (see below) The analysis of the results from a protocol, provided by Ciba-Geigy Company, showed a similar benefit in reducing both flexor and extensor spasticity in the legs. In addition, baclofen decreased clonus, flexor and extensor spasms, and their associated pain.

The most common side effects in this series were sedation, nausea, and

TABLE 1:

Grading of Spasticity

0

Normal - no spasticity

1 Increased deep tendon reflexes with a tendency for the leg to jerk several times before falling to the bed after passive flexion of the knee and hip

2 Same phenomenon as in No. 1 plus a slow drift (less than 15 seconds) of the leg to the bed

3 The drift is slower, between $15-30$ seconds

4 After passive flexion at the knee and hip, the leg will remain extended for a period of 30 seconds or more

5 In the absence of voluntary contraction, the leg will stay extended and require a significant degree of force to overcome the extensor spasticity 
vomiting (see Figure 1). The incidence of side effects, overall, was high, with $71 \%$ of the patients on the active agent having at least one side effect, compared to only $19 \%$ of those on placebo. This incidence is somewhat higher than that recently reported, although Sachais (1977) reported somnolence occurred in $75 \%$ of his patients. Fortunately, the side effects were usually well tolerated by the subjects. However, side effects did restrict the total dosage in two patients and accounted for withdrawal from the study in one. Increased weakness, such that walking became impaired, sometimes causing the patients to fall, occurred in three patients. This resulted in withdrawal from the study in one patient and restricted the maximum dosage in two. Two patients had an episode of neurological worsening, with signs and symptoms specific enough to allow a diagnosis of an exacerbation of MS - one in the placebo group and one in the active group. The exacerbations were mild, lasting from three to six weeks, with good recovery in each case. Two other patients had complaints other than increased weakness or balance disturbance, which seemed to be a worsening of their underlying condition. In these two cases, the symptoms were not specific enough to make a diagnosis of an acute relapse of MS. One of these patients was on placebo and other on baclofen. The symptoms were mild and did not restrict dosage or result in withdrawal from the study in either case.

There were no changes in blood pressure, pulse, hepatic, renal, or hematological function in any of the patients. One patient gained about 4 $\mathrm{kg}$. and described a bloating sensation of the abdomen and legs. Her blood pressure remained normal, and there was no evidence of edema. The symptoms regressed after stopping the baclofen. (This patient was later rechallenged with the drug on an open trial and again had similar symptoms without any weight gain).

Eleven patients were given the drug on a open trial basis for six months, with close follow-up. The dosage of baclofen ranged from 30 to $200 \mathrm{mg}$. per day. Seven patients continued to have sustained relief of spasticity. The drug had to be withdrawn from two patients who were taking up to $200 \mathrm{mg}$. per day. One of these patients developed a severe discomfort in the legs which necessitated discontinuing the drug. The second patient, although clearly benefitting from the drug,developed an acute depression which may or may not have been related to the use of baclofen.

\section{DISCUSSION}

Baclofen proved to be an effective drug in the treatment of spasticity in patients with MS. It resulted in sustained relief for at least six months. The authors were especially impressed with the ability of this drug to alleviate extensor and flexor spasms and the associated discomfort these spasms may cause. Sometimes the relief of these spasms was the only manifestation of the efficacy of the drug, as objective testing of tone failed to reveal any change. Patients were often delighted with the relief of spasms.

Secondly, it was found that the treatment of spasticity with baclofen was not uniformly beneficial in all patients. The authors could not find any clinical parameters which would predict which patients would respond and which would not. It was noted, however, that those patients who had no side effects were also those who had no response.

The frequency of side effects was found to be high in this series. In general, they were transient and occurred when the drug was being increased or the dosage was very high (eg. $200 \mathrm{mg}$. per day). The patients usually accommodated to the side effects quickly. There was a variable sensitivity from patient to patient in development of and the accomodation to the side effects.

It was disturbing to the authors that some patients deteriorated while using this drug. Several patients obviously required spasticity for support in walking. When this spasticity was withdrawn, their gait deteriorated dramatically. The authors concluded that the drug was not indicated in such patients. The drug seemed best indicated in non-ambulatory patients who do not require spasticity for any activities of daily living and in whom

Figure 1

Side Effects of Baclofen

\begin{tabular}{|c|c|c|c|}
\hline & \multicolumn{3}{|c|}{$\begin{array}{c}\text { MEAN } \\
\text { DURATION }\end{array}$} \\
\hline \multicolumn{4}{|l|}{ NEUROLOGICAL } \\
\hline SEDATION & $6(29)$ & 15 & $1,1,2,3,3,3$ \\
\hline HEADACHE & $3(14)$ & 6 & $3,3,3$ \\
\hline MOOD CHANGES & $4(19)$ & & \\
\hline EUPHORIA & $2(10)$ & 9 & 1,2 \\
\hline DEPRESSION & $2(10)$ & 9 & 3,3 \\
\hline DIZZINESS (NONSPECIFIC) & $2(10)$ & 16 & 1,1 \\
\hline BALANCE DISTURBANCE & $2(10)$ & 6 & 2,4 \\
\hline INCREASED WEAKNESS & $3(14)$ & 18 & $2,4,4$ \\
\hline \multicolumn{4}{|l|}{ GASTROINTESTINAL } \\
\hline NAUSEA & $5(24)$ & 8 & $1,2,2,3,4$ \\
\hline VOMITING & $2(10)$ & 5 & 2,2 \\
\hline DIARRHEA & $1(5)$ & 14 & 5 \\
\hline ABDOMINAL PAIN & $2(10)$ & 5 & 2,4 \\
\hline \multicolumn{4}{|l|}{ MISCELLANEOUS } \\
\hline GENERAL MALAISE & $2(10)$ & 14 & 2,2 \\
\hline DRY MOUTH & $1(5)$ & 16 & 2 \\
\hline \multirow[t]{2}{*}{ WEIGHT GAIN } & $1(5)$ & 21 & 3 \\
\hline & \multicolumn{3}{|c|}{$\begin{array}{l}1-\text { MILD } \\
2-\text { MODERATE } \\
3-\text { SEVERE } \\
4-\text { PROHIBITIVE }\end{array}$} \\
\hline
\end{tabular}


their spasticity was a hindrance to nursing and self-care.

It was even more disturbing to the authors that the use of the drug was associated with a definite relapse of the MS in one case. Although mild and short-lived, the possibility that this drug may have been responsible for the relapse is worthy of attention. Further study is required to ascertain whether the observed associated relapses of MS in this series were merely chance occurrences or actually precipitated by the drug.

The authors found it necessary to closely supervise their patients, when beginning the drug, because of the frequency of side effects and the problems of deterioration of function in some patients. Careful selection is necessary in order to avoid the use of baclofen in those patients whose spasticity is of obvious benefit in ambulation. Patients should be seen frequently and the dosage adjusted according to the reaction of the individual.

The authors recommend that the drug be given starting with small doses ( $5 \mathrm{mg}$. three or four times a day) taken with meals. The drug should be slowly increased every two or three days, or even longer, until a dosage of 60 to 80 mg. a day is reached. If weakness should occur, or severe side effects ensue, the drug should not be further increased or should be reduced or stopped. Only after the patient has accommodated to the side effects and/or increased weakness should the dosage of the drug be increased.
The authors conclude that baclofen is effective in treating spasticity in some patients with MS. Further studies with this drug are indicated.

\section{REFERENCES}

ASHBY, P., (1973) The Neurophysiology of Spasticity, J. of Canadian Physiotherapy Association, Oct. p. 203-212.

ASHBY, P. and WHITE, D. G. (1973) "Presynaptic" Inhibition in Spasticity and the Effects of B (4-chorophenyl) Gaba, J. Neurol. Sci. 20: 329-338.

BIRKMAYER, W., Ed. (1972) Spasticity: A Topical Survey. International Symposium, Vienna, 1971, Huber, Vienna, 1972.

BURKE, D., ANDREWS, C. J. and KNOWLES, L. (1971) The Action of a GABA Deriviative in Human Spasticity, J. Neurol. Sci. 14: 199-208.

CALNE, D. B. (1975) Drug Treatment of Spasticity and Rigidity, In: Modern Trends in Neurology 6, Butterworths, London and Boston, p. 205-221.

CURTIS, D. R., DUGGAN, A. W., FELIX, D., and JOHNSTON, G. (1971) Bicculline, an Antagonist of GABA and Synaptic Inhibition in the Spinal Cord, Brain Res. 32: 69-96.

CURTIS, D. R., GAME, C., JOHNSTON, G. and McCULLOCH, R. (1974) Central Effects of B - (p-Chlorophenyl) GammaAminobutyric Acid, Brain Res. 70; 493-499.

DAVIDOFF, R. and SEARS, E. S. (1974) The Effects of Lioresal on Synaptic Activity in the Isolated Spinal Cord, Neurology 24: 957-963.

FAIGLE, J. W. and KEBERLE, H. (1972) The Metabolism and Pharmacokinetics of Lioresal, in Spasticity; A Topical Survey, edited by W. Birkmeyer, Huber, Vienna, 1972.

FELDMAN, R, G., KELLY, HAYES, M., CONOMY, J. P. and FOLEY, J. N. (1978) Baclofen for Spasticity in Mulutiple Sclerosis, Neurol. 28: 1094-1098.
FROM, A. and HELTBERG, A. (1975) A Double-blind Trial with Baclofen (Lioresal) and Diazepam in Spasticity Due to Multiple Sclerosis, Acta. Neurol. Scandinav. 51: 158-166.

HUDGSON, P. and WRIGHTMAN, D. (1971) Baclofen in the Treatment of Spasticity, Bri. Med. J. 4: 15-17.

LANCET EDITORIAL (1970) Drug Treatment of Spasticity, Lancet 2: 918-919.

LANDAU, W. M. (1974) Spasticity: The Fable of a Neurological Demon and the Emperors New Therapy, Arch Neurol. 31: 217-219.

LAPIERRE, Y. D., ELIE, R., and TETREAULT, L. (1974) The Antispastic effect of Ba 3467. A GABA Derivative, Curr. Therapeut. Res., 16: 1059-1068.

PEDERSON, E., ARLIEND-SBORG, $P$. GRYNDERUP, V. and HENRIKSEN, $O$. (1970) GABA Derivative in Spasticity, Acta Neurol. Scandinav. 46: 257-266.

PINTO, $O$ de S., POLIKAR, $M$. and LOUSTALOT, P. (1972) A Review of Clinical Trials with Lioresal, in Spasticity; A Topical Survey, edited by W. Birkmeyer, Huber, Vienna, 1972

POLACEK, L. and SCHUPPIEN, W. (1972) Results of Four Years Experience with CIBA 34, 647-Ba (Lioresal) in the Treatment of Multiple Sclerosis, in Spasticity, A Topical Survey, edited by W. Birkmeyer, Huber, Vienna, 1972. p. 123-127.

ROBERTS, E. (1975) GABA in Nervous System Function - An Overview, In: The Nervous System, D. B. Tower, Editor-inChief Vol. 1: The Basic Neurosciences, Raven Press, New York, 1975. p. 541-552.

SACHAIS, B., LOGUE, J. N. and CAREY, M. S. (1977) Baclofen, A New Antispastic Drug, Arch. Neurol. 34: 422-428.

SAITO, K., KONISHI, S. and OTSUKA, M. (1975) Antagonism Between Lioresal and Substance $P$ in Rat Spinal Cord, Brain Res., 97: $177-180$ 